\title{
Application of Solidworks Application Programming Interface in Automobile Structural analysis
}

\author{
Rui Lyu ${ }^{1, a}$, Otake Minoru ${ }^{2, b}$ and Dongying Ju ${ }^{1, c, *}$ \\ ${ }^{1}$ Department of Electronic Science and Engineering, Saitama Institute of Technology University, \\ ${ }^{2}$ Manufacturing research center, Saitama Institute of Technology \\ alr518ever@gmail.com, bootake.minoru@sit.ac.jp, cdyju@sit.ac.jp \\ * Dongying Ju
}

Keywords: Solidworks, API, VBA, Base frame, Lightweighting

\begin{abstract}
The Solidworks Simulation Application Programming Interface (API) functionality can be used to automate the creation of studies, The API provides a powerful platform for automation as well as productivity gains for any user who needs to build custom inputs or outputs to drive Simulation studies or has to work past user interface limitations. This paper uses solidworks API to automatic analyse the new energy vehicle chassis frame structure. The process of material selecting, loading, meshing and the base frame model analysing could be accomplished by VBA automatically. Comparing the results of each steps, structure of the base flame is optimized and lightweighting.
\end{abstract}

\section{Introduction}

SolidWorks is a 3D drawing software based on Windows platform. It changes the design mode of traditional two-dimensional drawing, and uses feature modeling and parametric drive to design and modify 3D solid model conveniently. The two-dimensional engineering model can be automatically generated by using 3D solid model, which can dynamically simulate the assembly process and interfere with the inspection. It can also do the finite element analysis and optimization design of the important parts.

Solidworks API is divided into two kinds, one is the OLE Automation ID is based on patch technology, commonly used in Visual Basic and Delphi programming language interface, through the ID ispatch 13 exposure to the object properties and methods, in order to use these attributes and call the methods it supports in the client, the technology can develop.EXE the form of the program. Through the development of Solidworks DLL Dynamic API SolidWorks link Library dynamic link library) plug-in, the software can directly add in the SolidWorks system, realize the integration with SolidWorks; another way of development is based on COM, mainly used in the VC++ programming language 13. This technique allows you to use the most SolidWorks API (Application, Programming, Interface, application interface) functions.

\section{Solidworks API principle overview}

\subsection{SolidWorks's API interface}

Solidworks API offers a free, open and integrated development tools for the user, through OLE (object linking and embedding, object linking and embedding) technology provides functions for C, $\mathrm{C}++$, Visual Basic, VBA calls a large number of users, all functions are methods about the object or attribute, ability these functions provide direct access to the SolidWorks programmer.

\subsection{Solidworks API object model}

The Solidworks object is the highest level object in the SolidWorks API object model, which can access all other objects in SolidWorks API directly or indirectly. Solidworks objects include ModelDoc, Environment, Frame, AttributeDef, Modeler, SWPropertySheet, and some other objects. 


\section{The program design process}

\subsection{Material editing and Loading}

Using the command of Macro Operations in Solidworks, program of material selection could be generated in Visual Basic Language. And properties of materials could be rewritten directly through the program.

After selecting the material, the stress analysis of the model is carried out, Figure 1. Firstly, the load of the different parts of the model is restrained after the freedom of the end face is restrained.

\subsection{Meshing and Analysis}

In the choice of materials and loading after the needs of the model grid, then choose the size of the grid, to the small number of mesh complex $(30 \sim 40 \mathrm{~mm})$, the simple model can be set up a relatively large number of grid $(40 \sim 70 \mathrm{~mm})$. (as shown in Figure 2$)$. After the grid is divided, the analysis and calculation can be carried out.

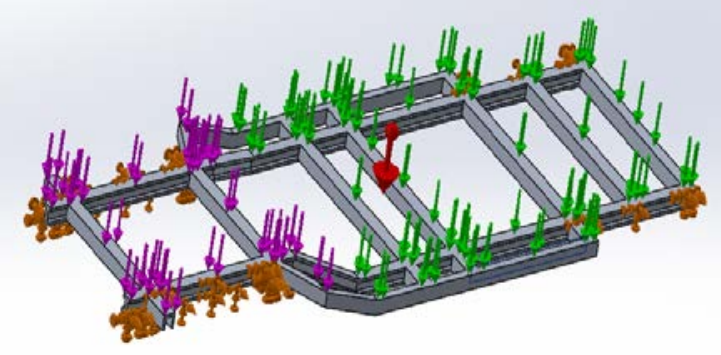

Figure 1 Boundary condition of Base frame model

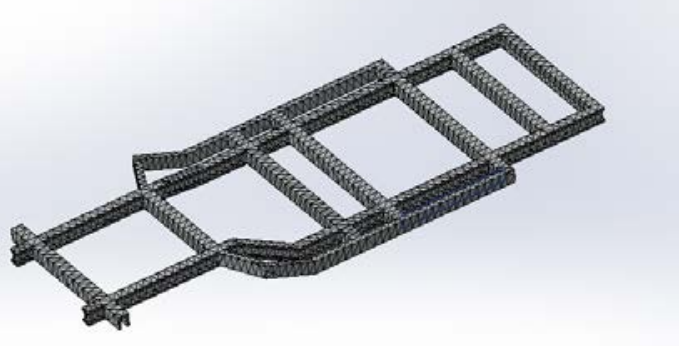

Figure 2 Mesh of Base frame model

\section{Example analysis of car model by using VBA}

In the Solidworks Software, all applications can use VBA (Visual, Basic, For, Application). VBA is an automated language that enables automation of commonly used programs and creates custom solutions.

In this study, the market is the target frame to design a lightweight vehicle base frame. Therefore, the optimal design of safety while satisfying the lightweight. In the optimum design, structural analysis, static, while adjusting the cross-sectional shape and material parameter, structure and material adopted by lightweight design method, and in addition, the structural static analysis, the following parameters are predicted.

\subsection{Model material selection and loading}

In this paper, three kinds of materials are used for the analysis and calculation of automobiles (Table 1). In the whole base frame by gravity condition, the $40 \%$ part of the loading car whole load model, the latter part of the $60 \%$ wh1ole car loading load, and the supporting force in the hub link loading chassis upward, making the car balance. 
Table 1 The mechanical properties of Aluminum, Steel and Magnesium

\begin{tabular}{c|c|c|c}
\hline & SPFH540 & $\begin{array}{c}\text { Aluminum } \\
\text { 6061-T6 }\end{array}$ & $\begin{array}{c}\text { Magnesium } \\
\text { AZ91 }\end{array}$ \\
\hline Density $\left(\mathrm{kg} / \mathrm{m}^{3}\right)$ & 7850 & 2700 & 1830 \\
\hline $\begin{array}{c}\text { Coefficient of } \\
\text { elasticity } \\
(\mathrm{MPa})\end{array}$ & 210 & 69 & 45 \\
\hline Poisson ratio & 0.3 & 0.33 & 0.35 \\
\hline $\begin{array}{c}\text { Tensile } \\
\text { strength(MPa) }\end{array}$ & 540 & 310 & 340 \\
\hline
\end{tabular}

\subsection{Calculation results}

Under the above conditions, the model of the base frame is analyzed and calculated, and the shape variables, maximum and minimum stresses of the model are obtained (Figure 3.4.5). Through the analysis and calculation of the chassis with different sectional area, the stress, deformation and weight ratio are obtained (Table 2), and achieved the purpose of optimizing the chassis 。

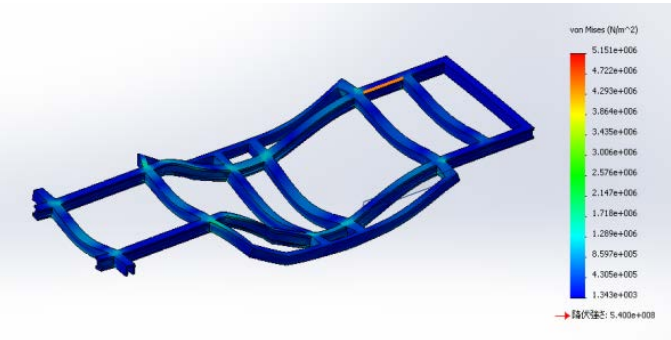

a. Von-Mises

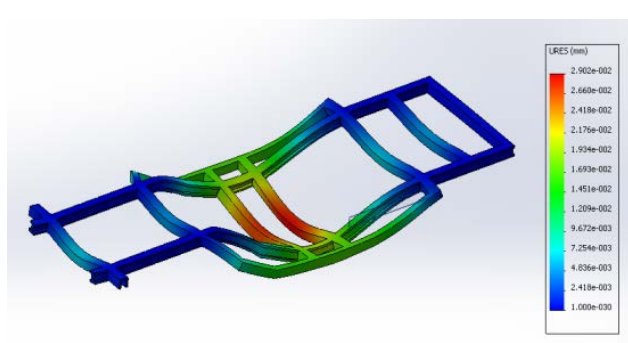

b. Deformation quantity

Figure 3 The calculation results of Steel base frame 


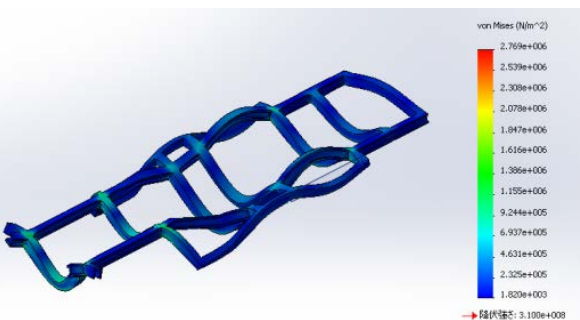

a. Von-Mises

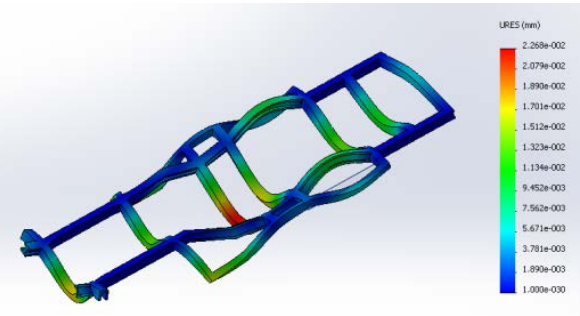

b. Deformation quantity

Figure 4 The calculation results of Aluminum base frame

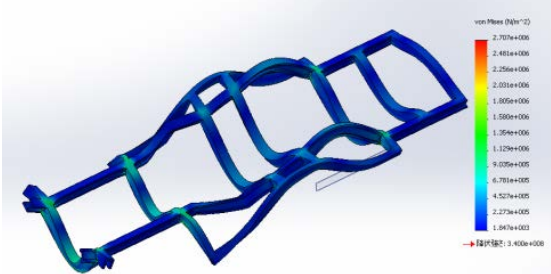

a. Von-Mises

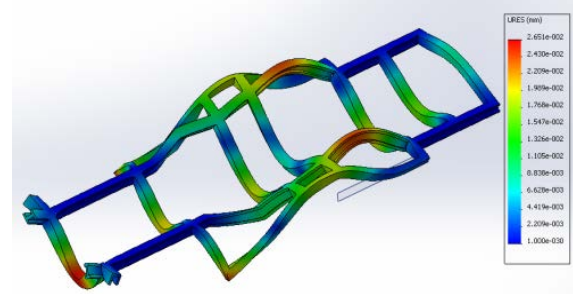

b. Deformation quantity

Figure 5 The calculation results of Magnesium base frame

Table 2 The analysis results of the frame optimization

\begin{tabular}{|c|c|c|c|c|c|}
\hline $\begin{array}{c}\text { Section } \\
\text { shape }\end{array}$ & $\begin{array}{c}\text { Height } \\
(\mathrm{mm})\end{array}$ & & SPF540 & 6061-T6 & AZ91 \\
\hline & & Weight & $377.14 \mathrm{~kg}$ & $129.72 \mathrm{~kg}$ & $87.918 \mathrm{~kg}$ \\
\hline & & $\triangle \mathrm{L}(\mathrm{mm})$ & $1.69 \mathrm{E}-05$ & 5.02E-05 & 7.27E-05 \\
\hline & 100 & $\bar{\sigma}(\mathrm{Pa})$ & $5.26 \mathrm{E}+06$ & $5.24 \mathrm{E}+06$ & $5.23 E+06$ \\
\hline & & $\sigma 1-\sigma 3(\mathrm{~Pa})$ & $5.56 \mathrm{E}+06$ & $5.55 \mathrm{E}+06$ & $5.55 \mathrm{E}+06$ \\
\hline & & Weight & $368.07 \mathrm{~kg}$ & $126.6 \mathrm{~kg}$ & $85.804 \mathrm{~kg}$ \\
\hline \multirow[t]{13}{*}{ П Type } & & $\triangle \mathrm{L}(\mathrm{mm})$ & $2.84 \mathrm{E}-05$ & 8.20E-05 & $1.26 \mathrm{E}-04$ \\
\hline & 90 & $\bar{\sigma}(\mathrm{Pa})$ & $7.54 \mathrm{E}+06$ & $5.26 \mathrm{E}+06$ & $4.85 E+06$ \\
\hline & & $\sigma 1-\sigma 3(\mathrm{~Pa})$ & $8.62 \mathrm{E}+06$ & $6.03 \mathrm{E}+06$ & $5.57 \mathrm{E}+06$ \\
\hline & & Weight & $339.83 \mathrm{~kg}$ & $116.89 \mathrm{~kg}$ & $79.222 \mathrm{~kg}$ \\
\hline & & $\Delta \mathrm{L}(\mathrm{mm})$ & 2.83E-05 & $8.20 \mathrm{E}-05$ & $1.25 \mathrm{E}-04$ \\
\hline & 80 & $\bar{\sigma}(\mathrm{Pa})$ & $5.88 \mathrm{E}+06$ & $4.97 \mathrm{E}+06$ & $4.90 E+06$ \\
\hline & & $\sigma 1-\sigma 3(\mathrm{~Pa})$ & $6.68 \mathrm{E}+06$ & $5.16 \mathrm{E}+06$ & $5.09 \mathrm{E}+06$ \\
\hline & & Weight & $365.16 \mathrm{~kg}$ & $125.6 \mathrm{~kg}$ & $85.126 \mathrm{~kg}$ \\
\hline & & $\Delta \mathrm{L}(\mathrm{mm})$ & $2.61 \mathrm{E}-05$ & 7.56E-05 & $1.16 \mathrm{E}-04$ \\
\hline & 100 & $\bar{\sigma}(\mathrm{Pa})$ & $7.66 \mathrm{E}+06$ & $5.23 E+06$ & $4.80 \mathrm{E}+06$ \\
\hline & & $\sigma 1-\sigma 3(\mathrm{~Pa})$ & $8.54 \mathrm{E}+06$ & $5.99 \mathrm{E}+06$ & $5.50 \mathrm{E}+06$ \\
\hline & & Weight & $357.18 \mathrm{~kg}$ & $122.85 \mathrm{~kg}$ & $83.267 \mathrm{~kg}$ \\
\hline & & $\triangle \mathrm{L}(\mathrm{mm})$ & 2.50E-05 & 7.25E-05 & $1.11 \mathrm{E}-04$ \\
\hline \multirow[t]{6}{*}{ 工 Туре } & 90 & $\bar{\sigma}(\mathrm{Pa})$ & $3.72 E+06$ & $3.02 \mathrm{E}+06$ & $3.01 \mathrm{E}+06$ \\
\hline & & $\sigma 1-\sigma 3(\mathrm{~Pa})$ & $3.99 \mathrm{E}+06$ & $3.12 \mathrm{E}+06$ & $3.12 \mathrm{E}+06$ \\
\hline & & Weight & $337.4 \mathrm{~kg}$ & $116.05 \mathrm{~kg}$ & $78.656 \mathrm{~kg}$ \\
\hline & & $\triangle \mathrm{L}(\mathrm{mm})$ & $1.32 \mathrm{E}-05$ & 3.83E-05 & 5.85E-05 \\
\hline & 80 & $\bar{\sigma}(\mathrm{Pa})$ & $5.88 \mathrm{E}+06$ & $5.52 \mathrm{E}+06$ & $5.51 \mathrm{E}+06$ \\
\hline & & $\sigma 1-\sigma 3(\mathrm{~Pa})$ & $6.77 \mathrm{E}+06$ & $6.04 \mathrm{E}+06$ & $6.04 \mathrm{E}+06$ \\
\hline
\end{tabular}

\section{Conclusion}

In this paper, a new method in analysing automobile base frame were carried out using the Solidworks software. Through the seamless integration of plug-in system with Solidworks software, using VBA programming method, calculation efficiency of the base frame model was improved, 
product design time was also shortened. Satisfying stress condition, the results show that Magnesium alloy frame is $70 \%$ lighter than iron frame,40\% lighter than aluminium frame, and the lightweight design was achieved.

\section{Acknowledgement}

This research receives ongoing support from the Next-Generation vehicle Project at Saitama Institute of Technology.

\section{Reference,}

[1]Guofu Yin, Xiangyun yin, Xiaobing Hiu. SolidWorks API Example [M]. Beijing:Machinery Industry Press,2006.

[2] Long Qian. Study on the optimum design of automotive frame using FEM .2106

[3] Gang Li, Cuiping Zhang, Lei Li. Visual Basic 6.0 foundations and examples of Chinese programming. Beijing: Electronics Industry Press,2000.

[4]Xiangyue Zhang. 3D modeling of SolidWorks API offshore platform by using VB, 2006.

[5]Qiqi Tan, Yanjie Luo, Jing Wang. Implementation of Solidworks embedded plug-in based on VB.NET [M]. Computer and network,2008. 